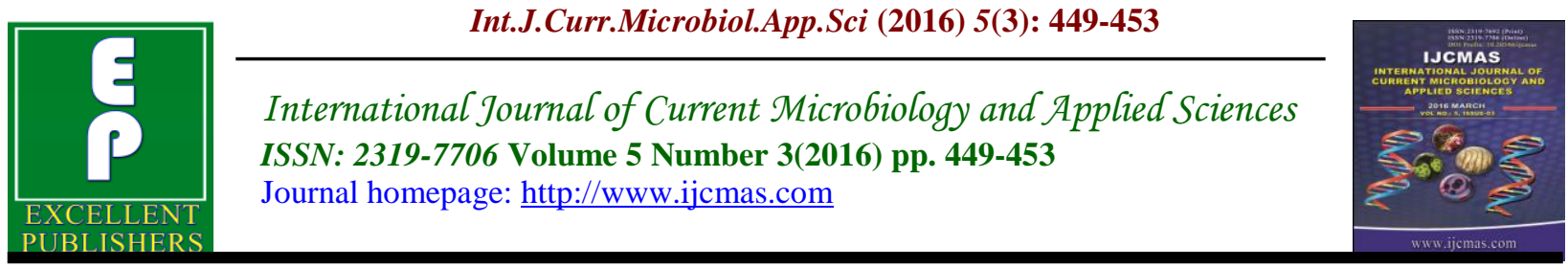

Original Research Article

http://dx.doi.org/10.20546/ijcmas.2016.503.052

\title{
Autoantibodies to Citrullinated Proteins in Serum of Positive Rheumatoid Factor
}

\author{
Nada Nadhir Basheer ${ }^{1}$, Suhad Tareq Rashid ${ }^{1}$, Muna Abdulrahman Hasan ${ }^{1}$, \\ Rhaghad Ali ${ }^{1}$ and Layla Fouad $\mathrm{Ali}^{2} *$ \\ ${ }^{1}$ Immunology Department, Central Public Health Laboratory, Ministry of Health, Iraq \\ ${ }^{2}$ Department of Biology, College of Science, University of Baghdad, Iraq \\ *Corresponding author
}

Keywords

Anti-CCP antibody,

Rheumatoid factor, Rheumatoid arthritis.

Article Info

Accepted:

18 February 2016

Available Online:

10 March 2016

\section{A B S T R A C T}

Serum samples were collected from 110 Iraqi patients suffering from joints disorders, 44 of them were RF positive results, 16 (\%36.4) out of them had positive anti-CCP and $28(63.6 \%)$ had negative results for anti-CCP. In this study it is concluded that not all patients with positive RF have positive antiCCP results, which means that they may have any rheumatoid inflammation other than rheumatoid arthritis.

\section{Introduction}

Rheumatoid arthritis (RA) is a systemic autoimmune disease of unknown origin, which characterized by chronic joint inflammation that may later develop into joint destruction, as well as functional limitation (Pincus et al., 1984). As a matter of fact, the diagnosis of early RA is quite impossible, because the clinical criteria are insufficient at the beginning stage of the disease. In 1998, Schelleken reported that a high percentage of RA patients had a specific antibody that could interact with a synthetic peptide contained the amino acid citrulline. The high specificity $(98 \%)$ for RA of this new serological marker, anti-cyclic citrullinated antibody (anti-CCP antibody), can be detected early in RA, before the clinical features appear (Scott et al., 1987).
So far, the diagnosis has mainly depended on the clinical manifestations. The laboratory test which may contribute to the diagnosis of RA is rheumatoid factor (Bas et al., 1987). However, the positive rate is approximately $70 \%$. as many rheumatic or immune diseases, including systemic lupus erythematosus (SLE), Sjogren's syndrome (SS), primary cryoglobulinemia and viral infection or tumor may develop positive RF, the specificity of RF in RA is apparently lower (Rantapaa-Dahlqvist et al., 2003).

Therefore, it is necessary to search for other laboratory diagnostic markers with high sensitivity and specificity. The introduction of test recognizing the 'anti-citrullinated 
protein antibodies' (ACPA) has caused a revolution in rheumatology. Immunization against citrullinated proteins is a feature almost unique for rheumatoid arthritis, although ACPA may occur long before the onset of symptoms. Even if the presence of ACPA does not seem to reveal a distinct arthritis phenotype at symptom onset, it predicts an aggressive disease course with unfavourable outcome. Despite the high diagnostic specificity for rheumatoid arthritis, ACPA-positivity does not always accord with a traditional diagnosis of rheumatoid arthritis at clinical presentation. However, even when these patients are judged to suffer from mild undifferentiated arthritis, they have special attention by rheumatologists.

Since 1960, many investigators used indirect immunoflurorescence or enzyme-linked immunosorbent tests to detect serologic antibodies in RA patients (Bas et al., 2000).

Citrulline is an unusual amino acid which formed by posttranslational modification of arginine residues by the enzyme peptidyl arginine deaminase (Schellekens et al., 2000). Recombinant filaggrin fragments, after enzymatic deamination, in vitro, react with autoantibodies in RA sera. Synthetic cyclic citrullinated peptide (CCP) variants also react with anti-filaggrin autoantibodies and serve as the substrate for detecting antiCCP antibodies serologically. Most studies of anti-CCP antibodies demonstrated that these autoantibodies have improved specificity for RA compared to RF (Visser et al., 2002). Schelleken in 1988 reported that $76 \%$ of RA patients had a specific antibody which could interact with a synthetic peptide that contained the amino acid citrulline (Schellekens et al., 1998). This modification actually improves the specificity up to $98 \%$. Sensitivity recently increased to $80 \%$ after using the 2nd generation anti-CCP enzyme-linked immunosorbent test (ELISA) (Dubucquoi et $a l ., 2004)$. Many studies have focused on the value of the clinical application of anti-CCP antibody in rheumatoid arthritis and other rheumatic diseases (Forslind et al., 2004). The high specificity (98\%) of anti-CCP in patients with RA can exclude other rheumatic or immune diseases in positive patients for anti-CCP (Anzilotti et al., 2006). In addition, the anti-CCP antibody test may help us to detect or recognize RA earlier (Russell et al., 2006). Many recent studies have shown that the anti-CCP antibody can predict the severity of either the clinical or radiological outcome in RA patients (Kastbom et al., 2004; Meyer et al., 2003). Aotsuka et al. measured anti-CCP antibody in RA patients during the period 1982-2004 and found that anti-CCP levels tended to fluctuate in parallel with the ESR and CRP level (Aotsuka et al., 2005).

The main objectives of this study includes, to evaluate the diagnostic of antibodies to $\mathrm{RF}$ and cyclic citrullinated peptide (CCP) in patients with joints disorder.

\section{Materials and Methods}

110 serum samples were collected from Iraqi patient suffering from joint pain in Central Republic Health Center Laboratories, Immunonology department. These samples were analysed by an enzyme immunoassay (ELISA) for IgM RF, IgG RF, IgA RF (IMMCO, USA) test and the positive samples used for anti-CCP test using ELISA Kit (IMMCO, USA) and the procedures were done according to the kits instructions.

\section{Results and Discussion}

A total of 110 patients, 44 of them were RF positive results, $16(\% 36.4)$ out of them had 
positive anti-CCP and 28 (63.6\%) had negative results for anti-CCP.

Apart from pain and functional impairments, rheumatoid arthritis (RA) is associated with increased co morbidity and mortality, mainly due to coronary heart disease.

Rheumatoid factor (RF) test is widely used, although the diagnostic and prognostic information provided has been debated (Klareskog et al., 2005), Other inflammatory conditions and high age are considered "risk factors" for false positive RF. The sensitivity for diagnosis of RA has been reported to be $50-80 \%$ and the specificity 70-80\% (Thomas et al., 2005).

The criterion IgM-RF $>40$ or anti-CCP $>50$ can be able to predict the diagnosis of RA in early arthritis patients with high specificity and acceptable sensitivity. Anti-CCP testing combined with IgM-RF testing has additional value over IgM-RF testing alone in patients with early undifferentiated arthritis (Jansen et al., 2002). The high diagnostic specificity of anti-CCP for RA raises the question of an aetiopathogenetic connection. Comparisons of the prognostic value of $\mathrm{RF}$ and anti-CCP measured as radiological progression have shown different results (Vencovsky et al., 2003).

A study confirms that the diagnostic sensitivity of anti-CCP antibodies in patients with recent onset RA is the same as that of agglutinating RF (64\% for both) and that seropositivity for the two tests correlates significantly (Kastbom et al., 2004). An interesting finding was that the anti-CCP antibody positivity at diagnosis predicted higher disease activity over the 3 following years of recent onset RA (Jonsson et al., 1992).

The anti-CCP antibody results correlated with RF, but were better than RF as predictor of a more aggressive disease course. The anti-CCP antibody assay has a similar diagnostic sensitivity to that of RF in early RA, but is better as a predictor of the disease course over 3 years. Although the mean serum level declines, the anti-CCP antibody positivity remains essentially unaltered 3 years after diagnosis and start of antirheumatic treatment (Kastbom et al., 2004). It was conclude that anti-CCP antibody status at the time of diagnosis of early RA is a valuable predictor of the disease course in early RA (Jonsson et al., 1992). Further studies are needed to evaluate the usefulness of anti-CCP antibody analysis for design of the individual therapeutic strategies in early RA.

Anti-CCP has become a "key" serologic marker in RA. It can be used as a test for early diagnosis of RA and for the differential diagnosis between RA and other rheumatic or immune diseases. Furthermore it can be used for prediction of prognosis; and for evaluation of treatment outcome.

\section{References}

Anzilotti, C., Merlini, G., Pratesi, F., et al. 2006. Antibodies to viral citrullinated peptide in rheumatoid arthritis. $J$. Rheumatol., 33: 647-51.

Aotsuka, S., Okawa-Takatsuji, M., Nagatani, K., et al. 2005. A retrospective study of the fluctuation in serum levels of anti-cyclic citrullinated peptide antibody in patients with rheumatoid arthritis. Clin. Exp. Rheumatol., 23: 475-81.

Bas, S., Genevay, S., Meyer, O., et al. 1987. Anti-cyclic citrullinated peptide antibodies, IgM and IgA rheumatoid factors in the diagnosis and prognosis of rheumatoid arthritis. Rheumatol., 42: 677-80. 
Bas, S., Perneger, T.V., Mikhnevitch, E., et al. 2000. Association of rheumatoid factors and anti-filaggrin antibodies with severity of erosions in rheumatoid arthritis. Rheumatol., 39: 1082-8.

Dubucquoi, S., Solau-Gervais, E., Lefranc, D., et al. 2004. Evaluation of anticitrullinated filaggrin antibodies as hallmarks for the diagnosis of rheumatic diseases. Ann. Rheum. Dis., 63: 415-9.

Forslind, K., Ahlmen, M., Eberhardt, K., et al. 2004. Prediction of radiological outcome in early rheumatoid arthritis in clinical practice: role of antibodies to citrullinated peptides (antiCCP) Ann. Rheum. Dis., 63: 1090-5.

Jansen, A.L., Van der Horst-Bruinsma, Van Schaardenburg, Van de Stadt, R.J., De Koning, M.H., Dijkmans, B.A. 2002. Rheumatoid factor and antibodies to cyclic citrullinated Peptide differentiate rheumatoid arthritis from undifferentiated polyarthritis in patients with early arthritis. $J$. Rheumatol., 29(10): 2074-6.

Jonsson, T., Thorsteinsson, J., Kolbeinsson, A., Jonasdottir, E., Sigufsson, N., Vaaldimarsson, H. 1992. Population study of the importance of rheumatoid factor isotypes in adults. Ann. Rheum. Dis., 51: 863-8.

Kastbom, A., Strandberg, G., Lindroos, A., et al. 2004. Anti-CCP antibody test predicts the disease course during 3 years in early rheumatoid arthritis (the Swedish TIRA project) Ann. Rheum. Dis., 63: 1085-9.

Kastbom, A., Strandberg, G., Lindroos, A., Skogh, T. 2004. Author Affiliations Anti-CCP antibody test predicts the disease course during 3 years in early rheumatoid arthritis (the Swedish TIRA project). Ann. Rheum. Dis., 63: 108-58.
Klareskog, L., Stolt, P., Lundberg, K., Källberg, H., Bengtsson, C., Grünewald, J., Rönnelid, J., Erlandsson, Harris, H., Ulfgren, A.K., Rantapää-Dahlqvist, S., et al. 2005. A new model for an etiology of RA: smoking may trigger HLA-DR (SE)restricted immune reactions to autoantigens modified by citrullination. Arthritis Rheum.

Meyer, O., Labarre, C., Dougados, M., et al. 2003. Anticitrullinated protein/peptide antibody assays in early rheumatoid arthritis for predicting five-year radiographic damage. Ann. Rheum. Dis., 62: 120-6.

Pincus, T., Callahan, L.F., Sale, W.G. 1984. Severe functional declines, work disability, and increased mortality in seventy-five rheumatoid arthritis patients studied over nine years. Arthritis Rheum., 27: 864-72.

Rantapaa-Dahlqvist, S., De Jong, B.A., Berglin, E., et al. 2003. Anti-bodies against cyclic citrullinated peptide and $\operatorname{IgA}$ rheumatoid factor predict the development of rheumatoid arthritis. Arthritis Rheum., 48: 27419.

Russell, A.S., Devani, A., Maksymowych, W.P. 2006. The role of anti-cyclic citrullinated peptide antibodies in predicting progression of palindromic rheumatism to rheumatoid arthritis. $J$. Rheumatol., 33: 1240-2.

Schellekens, G.A., De Jong, B.A.W., Van Den Hoogen, F.H.J., et al. 1998. Citrulline is an essential constituent of antigenic determinants recognized by rheumatoid arthritis-specific autoantibodies. J. Clin. Invest., 101: 273-81.

Schellekens, G.A., Visser, H., De Jong, B.A., et al. 2000. The diagnostic properties of rheumatoid arthritis antibodies recognizing a cyclic 
citrullinated peptide. Arthritis Rheum., 43(1): 155-163.

Scott, D.L., Symmons, D.P., Coulton, B.L., et al. 1987. Long-term outcome of treating rheumatoid arthritis: results after 20 years. Lancet, 1: 1108-11.

Thomas, S. 2005. Does a positive anti-CCP test identify a distinct arthritis entity. Arthritis Res. Ther., 7(6): 230-232.

Vencovsky, J., Machacek, S., Sedova, L., Kafkova, J., Gatterova, J., Pesakova,
V., et al. 2003. Autoantibodies can be prognostic markers of an erosive disease in early rheumatoid arthritis. Ann. Rheum. Dis., 62: 427-30.

Visser, H., Le Cessie, S., Vos, K., et al. 2002. How to diagnose rheumatoid arthritis early: a prediction model for persistent (erosive) arthritis. Arthritis Rheum., $\quad$ 46(2): $\quad 357-365$.

\section{How to cite this article:}

Nada Nadhir Basheer, Suhad Tareq Rashid, Muna Abdulrahman Hasan, Rhaghad Ali and Layla Fouad Ali. 2016. Autoantibodies to Citrullinated Proteins in Serum of Positive Rheumatoid Factor. Int.J.Curr.Microbiol.App.Sci. 5(3): 449-453. doi: http://dx.doi.org/10.20546/ijcmas.2016.503.052 